\title{
Lead-Soft and Easy to Cast
}

As part of a broad mission to conduct research and provide information on nonfuel mineral resources, the U.S. Geological Survey (USGS) supports science to understand

- How and where lead resources form and concentrate in the Earth's crust

- How lead resources interact with the environment to affect human and ecosystem health

- Trends in the supply of and demand for lead in the domestic and international markets

- Where future lead resources might be found

Why is this information important? Read on to learn about lead and the important role it plays in the national economy, national security, and lives of Americans every day.

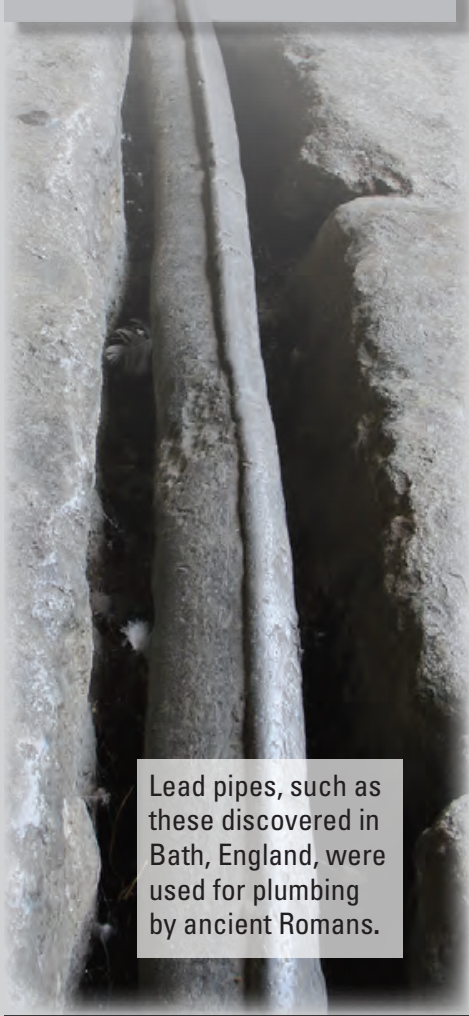

Lead is a corrosion-resistant dense metal that is easily molded and shaped. The chemical symbol for lead, $\mathrm{Pb}$, is an abbreviation of the Latin word plumbum, meaning soft metal. Archeological research indicates that lead has been used by humans for a variety of purposes for more than 5,000 years. Water pipes that date back to the Roman Empire, glazes on prehistoric ceramics, and the cosmetic kohl, used by ancient Egyptians to darken their eyelids, are a few examples of ancient uses of lead. Today, lead, which has been mined on all continents except Antarctica, is one of the most important metals to industrialized economies.

Lead is rarely found in native form in nature but it combines with other elements to form a variety of interesting and beautiful minerals. Galena, which is the dominant lead ore mineral, is blue-white in color when first uncovered but tarnishes to dull gray when exposed to air.

Scientific research demonstrating how accumulated ingested lead is toxic to human health and how accumulations of lead in the soil, air, and water are toxic to ecosystems is changing both how lead is used and how it is disposed of after use.

\section{How Do We Use Lead?}

Prior to the early 1900 s, lead was used in the United States primarily in ammunition, burial vault liners, ceramic glazes, leaded glass and crystal, paints or other protective coatings, pewter, and water lines and pipes. Following World War I, the demand for lead increased because of growth in the production of motorized vehicles, many of which use lead-acid batteries to start their engines. The use of lead as radiation shielding in medical analysis and video display equipment and as an additive in gasoline also contributed to an increase in the demand for lead.

According to the U.S. Agency for Toxic Substances and Disease Registry, environmental levels of lead have increased more than 1,000-fold over the past three centuries as a result of human activity. The greatest increase took place between 1950 and 2000 and reflected the increased use of leaded gasoline worldwide. During this period, the U.S. Government established Federal regulations and made recommendations to limit lead emissions to protect public health in the United States.

By the mid-1980s, a significant shift in the uses of lead had taken place in the United States as a result of compliance with environmental regulations and the substitution of other materials for lead in nonbattery products, such as gasoline, paints, solders, and water systems. By the early $2000 \mathrm{~s}, 88$ percent of apparent U.S. lead consumption was in lead-acid batteries, which was a substantial increase from 1960 when only 30 percent of global lead consumption was in lead-acid batteries. Today, the other significant uses of lead are in ammunition, oxides in glass and ceramics, casting metals, and sheet lead.

\section{Where Does Lead Come From?}

Research to better understand the geologic processes that form mineral deposits, including those containing lead, is an important component of the USGS Mineral Resources Program. Lead commonly occurs in mineral deposits along with other base metals, such as copper and zinc. Lead deposits are broadly classified on the basis of how they are formed. Lead is produced mainly from three types of deposits: sedimentary exhalative (Sedex), Mississippi Valley type (MVT), and volcanogenic massive sulfide (VMS).

Sedex deposits account for more than 50 percent of the world's lead resources. They are formed when metal-rich hot liquids are released into a water-filled basin (usually an ocean) or in basin sediments, which results in the precipitation of ore-bearing material within basin-floor sediments.

MVT deposits are found throughout the world and get their name from deposits that occur in the Mississippi Valley region of the United States. The deposits are characterized by ore mineral replacement of the carbonate host rock; they are often confined to a single stratigraphic layer and extend over hundreds of square kilometers. MVT deposits were a major source of lead in the United States from the 19th century through the mid-20th century.

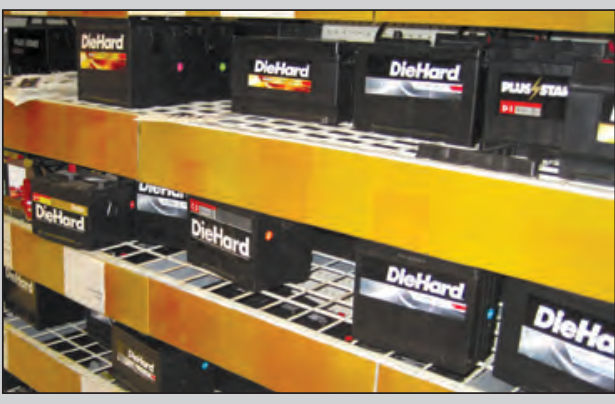

Typical lead-acid ignition batteries in automobiles contain about 10 kilograms of lead and need to be also supply standby power for computer networks storage for wind and solar energy systems and hybrid-electric vehicles.

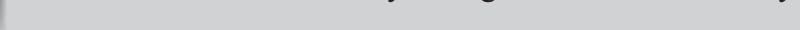


